\title{
Photoactive organic-inorganic hybrid polymer waveguides for optical device technologies
}

Collins, A., Southern, T. J., Lyu, G., Bennison, M., Evans, $\mathrm{R}$.

A. R. Collins, T. J. F. Southern, G. Lyu, M. J. Bennison, R. C. Evans, "Photoactive organic-inorganic hybrid polymer waveguides for optical device technologies," Proc. SPIE 11367, Photosensitive Materials and their Applications, 113670Y (1 April 2020); doi: 10.1117/12.2564510

SPIE. Event: SPIE Photonics Europe, 2020, Online Only, France 


\title{
Photoactive organic-inorganic hybrid polymer waveguides for optical device technologies
}

\author{
A. R. Collins, T. J. F. Southern, G. Lyu, M. J. Bennison, R. C. Evans* \\ Department of Materials Science and Metallurgy, University of Cambridge, 27 Charles Babbage \\ Road, Cambridge, United Kingdom CB3 OFS
}

\begin{abstract}
Organic-inorganic hybrid polymers based on ureasils have found application as waveguides in luminescent solar concentrators and visible light communications. The mechanical properties, and thus processability of ureasils, has previously been qualitatively linked to the chemical structure, but has not yet been studied in detail. In this study, a series of low molecular weight ureasil polymers has been synthesised, and the correlation between the chemical structure and the optical and mechanical properties investigated. A wide-range of techniques are employed to investigate this relationship, including steady-state photoluminescence and Fourier-transform infrared spectroscopy, 4-point flexural testing, and uniaxial tensile testing.
\end{abstract}

Keywords: Ureasils, waveguides, organic-inorganic hybrid materials, luminescent solar concentrators, visible light communications

\section{INTRODUCTION}

Materials for use as optical waveguides have a number of requirements to be suitable for purpose, most notably a high refractive index, optical clarity and high transmittance. These requirements have traditionally limited the materials used to glass or plastics such as poly(methyl methacrylate) and poly(carbonate). In more recent years several new materials have been investigated as alternatives, including poly(lactic acid), ${ }^{1}$ sol-gel glasses such as silica-zirconia and silicatitania, ${ }^{2}$ poly(siloxanes), ${ }^{3}$ and silsesquioxanes. ${ }^{4}$

Ureasils have recently been developed as a particularly interesting family of hybrid organic-inorganic materials for a range of applications, including luminescent solar concentrators, ${ }^{5}$ integrated optical substrates, ${ }^{6}$ electrochromic windows ${ }^{7}$ and visible light communications. ${ }^{8}$ They are typically prepared by reaction between a commercially available poly(ether)amine and a silica-functionalised isocyanate, before hydrolysis and condensation of the silica network using sol-gel chemistry. ${ }^{9}$ The mechanical properties of the ureasils have previously been qualitatively linked to the degree of branching and/or molecular weight of the poly(ether)amine backbone, ${ }^{10}$ with branched, low molecular weight backbones leading to more glass-like materials, and high molecular weights leading to more flexible matrices. Understanding and quantifying this relationship is of critical importance in order to both process and deploy ureasil waveguides in the optimum format for a given application.

In this work we have synthesised a series of low molecular weight ureasil polymer waveguides, allowing for investigation of the key structure-property relationships, between the variation in the structure of the polymeric precursor and both the optical and mechanical properties of the final gelled waveguide materials.

\section{EXPERIMENTAL}

\section{Materials}

Bis(2-aminopropyl) poly(propylene glycol)-block-poly(ethylene glycol)-block-poly(propylene glycol) (JEFFAMINE ${ }^{\circledR}$ ED-600, $\mathrm{Mw}=600 \mathrm{~g} \mathrm{~mol}^{-1}$ ), and 3-(triethoxysilyl)propylisocyanate (ICPTES, 95.0\%) were purchased from Sigma-

\footnotetext{
*Corresponding author: Dr Rachel C. Evans (rce26@cam.ac.uk)
} 
Aldrich. Tetrahydrofuran (THF, $\geq 99.9 \%$ ), ethanol (95.0\%), and hydrochloric acid (37\%) were purchased from Fisher Scientific. Water was obtained from a Millipore Simpak 2 water purification system. All materials were used as received.

JEFFAMINE ${ }^{\circledR} \mathrm{D}-\mathrm{X}$ and T-X ( $D$ denotes bis-end functionality, $T$ denotes tris-end functionality, and $X$ is representative of the molecular weight), poly[oxy(methyl-1,2-ethanediyl)], $\alpha$-(2-aminomethylethyl)- $\Omega$-(2-aminomethylethoxy) $\left(\right.$ JEFFAMINE $\left.{ }^{\circledR} \mathrm{D}-400, \mathrm{Mw}=430 \mathrm{~g} \mathrm{~mol}^{-1}\right)$, and glyceryl poly(oxypropylene) triamine (JEFFAMINE ${ }^{\circledR} \mathrm{T}-403, \mathrm{Mw}=440$ $\mathrm{g} \mathrm{mol}^{-1}$ ) were purchased from Huntsman.

\section{Fabrication of organic-inorganic hybrid ureasils}

Organic-inorganic hybrid ureasils were prepared via a two-step sol-gel process. ICPTES is mixed with JEFFAMINE ${ }^{\circledR}$ in a molar ratio of 2:1 for bis-functionalised amines and 3:1 for tris-functionalised amines in THF. The reaction mixture was refluxed at $70{ }^{\circ} \mathrm{C}$ for $24 \mathrm{~h}$ to obtain the organic-inorganic hybrid precursor, diureapropyltriethoxysilane (d-UPTES) or triureapropyltriethoxysilane (t-UPTES) in solution. In the second step, gelling reagents were sequentially added (ethanol, $\mathrm{HCl}(0.5 \mathrm{M})$ and water) to either d-UPTES or t-UPTES and thoroughly mixed. The molar ratio of ICPTES:ethanol:HCl:water used was 176:350:1:265. The resulting mixture was poured into a polypropylene mould and gelled into free-standing monoliths. The mould was sealed with Parafilm $\mathrm{M}^{\circledR}$ to ensure slow evaporation of the excess THF in the samples over 3-5 days, followed by further oven drying at $35^{\circ} \mathrm{C}$ for $3-5$ days, depending on the sample shrinkage rate.

\section{Ultraviolet/visible transmittance spectroscopy}

UV/Vis transmittance spectra were measured with a PerkinElmer Lambda 750 spectrophotometer using wavelength scan with a resolution of $1 \mathrm{~nm}$ at a scan speed of $267 \mathrm{~nm} / \mathrm{min}$ and a slit width of $2 \mathrm{~nm}$. Samples were directly mounted to the sample holder.

\section{Steady-state photoluminescence (PL) spectroscopy}

Steady-state PL spectroscopy was performed on a Fluorolog-3 spectrophotometer (Horiba Jobin Yvon). Solid-state emission spectra were recorded using the front-face configuration. The excitation and emission slits were adjusted so that the maximum PL intensity was within the range of linear response of the detector and were kept the same between samples if direct comparison between the emission intensity was required. Emission and excitation spectra were corrected for the wavelength response of the system and the intensity of the lamp profile over the excitation range, respectively, using correction factors supplied by the manufacturer.

\section{Fourier transform infrared spectroscopy}

Infrared spectra were obtained using a Nicolet iS5 (ThermoFisher instruments) Fourier transform infrared (FTIR) spectrometer fitted with an attenuated total reflectance (ATR) diamond press at room temperature over a range of 4000$400 \mathrm{~cm}^{-1}$ with a resolution of $0.5 \mathrm{~cm}^{-1}$, averaging 64 scans. Deconvolution of the Amide I region $\left(1800-1600 \mathrm{~cm}^{-1}\right)$ was performed using a non-linear least square (NLLS) fit to a combination of Gaussian or Voigt functions in Origin 2019 (OriginLab) software. The quality of all fits were assessed qualitatively by comparison of the cumulative fit peak (given by the sum of the intensity of each of the fitted peak at a given $x$ value) to the raw data.

\section{Mechanical testing}

4-point flexural testing and uniaxial tensile testing was performed on a Tinius Olsen 1ST using a $25 \mathrm{~N}$ load cell. Samples were cut into tensile specimens using a HPC Laser Ltd. Laserscript LS3060 to produce a $15 \mathrm{~mm} \times 5 \mathrm{~mm}$ testing area with a $4.5 \mathrm{~mm}$ gripping area at the ends. In the 4-point geometry, samples were placed on supports $12 \mathrm{~mm}$ apart and loaded from above at a speed of $10 \mathrm{~mm} \cdot \mathrm{min}-1$ by two loading points separated by $4 \mathrm{~mm}$. The force and corresponding displacement on these loading points was recorded until the point at which the loading points were compressing rather than bending the sample. In the uniaxial tensile geometry, samples were gripped at both ends and pulled apart at a speed of $1 \mathrm{~mm} \cdot \mathrm{min}-1$ until failure was observed. The force and corresponding displacement of the grips was recorded until failure. The datasets were analysed in Origin 2019 (OriginLab) to generate the elastic and flexural moduli of the samples from the gradient of the initial straight region of the stress-strain (first 100 data points) or force-extension curves (first 500 data points), respectively. In the case of the 4-point geometry, the experimental data was first transformed by multiplying the force required for deflection by a sample-dependent constant, $k$, and plotted against the position of the grips. This constant was determined from $k=\left(\frac{5 a^{3}}{6 L}\right)$, where $a$ is the distance between loading points $(4 \mathrm{~mm})$ and $I$ is the 
second moment of area of the sample about the bending neutral axis. $I$ was calculated from $I=\frac{b h^{3}}{12}$, where $b$ is the width of the sample and $h$ is the sample thickness.

\section{Water contact angle measurements}

The hydrophilicity of the monolith surfaces was investigated by measuring the water contact angle using an FTA $1000 \mathrm{~B}$ Class Drop Shape instrument, which uses the sessile droplet method. The water contact angle was found by averaging the angle from a minimum of five repeat measurements after the droplet had stabilised.

\section{RESULTS AND DISCUSSION}

\section{Synthesis}

Ureasils are typically prepared in a two-step reaction as shown in Figure 1. In the first step, ICPTES is reacted with a commercial Jeffamine ${ }^{\circledR}$ to form the intermediate di- or tri-ureapropyltriethoxysilane (d-UPTES or t-UPTES, respectively), depending on the number of terminal amine groups in the polyetheramine. In the second step, acidcatalysed hydrolysis of the ethoxysilane groups and subsequent condensation results in the formation of the siliceous framework, yielding the corresponding di- or tri-ureasil. Ureasils synthesised from Jeffamines ${ }^{\circledR}$ D- 400 or T-403, referred to as DU(400) and TU(403) respectively, consist of a poly(propylene glycol) homopolymer with either a linear difunctional, or branched trifunctional structure respectively. The ureasil synthesised from Jeffamine ${ }^{\circledR}$ ED-600, referred to as $\mathrm{dU}(600)$, consists of a linear, difunctional ABA triblock copolymer of poly(propylene glycol)- $b$-poly(ethylene glycol)- $b$-poly(propylene glycol). These structures were chosen to enable us to probe the effect of subtle changes to to the degree of branching, chemical structure and/or molecular weight of the polymer backbone on the mechanical properties of the resultant ureasil.
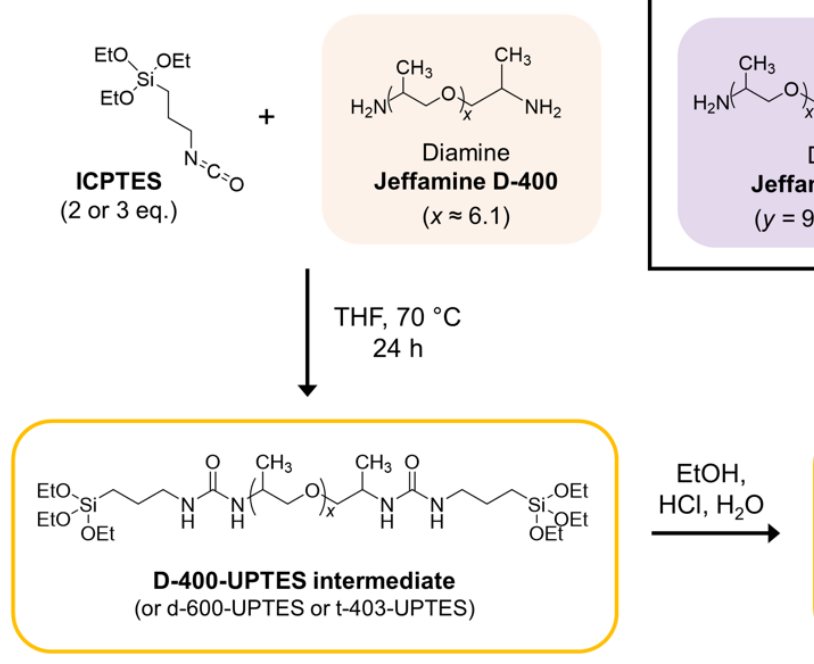

Figure 1 - Synthesis of di- or tri-ureasils starting from 3-(triethoxysilyl)propylisocyanate (ICPTES) and di- or tri-amine functionalised oligomers, followed by hydrolysis and condensation to form siliceous crosslinked domains

\section{Optical properties}

Unlike other waveguides, ureasils exhibit distinctive photoluminescence (PL) properties in the UV-blue region of the optical spectrum. Figure 2a shows photographs of a representative ureasil sample, DU(400). The DU(400) monolith shows excellent optical clarity and transparency under daylight conditions and strong blue PL when irradiated with UV 
light $(365 \mathrm{~nm})$. The UV/Vis transmittance spectrum of all di- and tri-ureasils synthesised in this study are shown in Figure $2 \mathrm{~b}$. All samples exhibit high transmittance of $>80 \%$ in the visible region, which is comparable to commonly used waveguide materials such as PMMA and glass, hence demonstrating the suitability of ureasils as waveguide materials for a diverse range of optical applications. The PL quantum efficiency of the spectral conversion offered by ureasil ranges from approximately 4 to $10 \%$, depending on the polymeric structure of the organic precursor (Jeffamine ${ }^{\circledR}$ ) used to synthesise the hybrid material. ${ }^{11,12,13}$ A previous study demonstrated that excitation energy transfer can occur from a diureasil host to the embedded lumophores with appropriate spectral overlap, via the Förster resonance energy transfer (FRET) mechanism. ${ }^{14}$ This unique optical feature of the ureasil host material therefore offers the possibility for enhancing the optical activity of the resulting light-guiding devices across a wider range of the UV-visible spectrum. Figure 2c shows the PL emission spectra of DU(400) excited at various wavelengths. Notably, the emission maximum of the di-ureasil shifts to lower energy with increasing excitation wavelength, which is common for ureasil materials. This is a result of the di-ureasil emission arising from two distinct contributions: a longer-wavelength (blue) and a shortwavelength (blue-purple) component, ascribed to the donor-acceptor electron-hole recombination occurring at the urea linkages via proton transfer and at the siliceous nanodomains through the localized oxygen defects, respectively. ${ }^{13}$ Depending on the excitation wavelength, one of the two emission components will be selectively excited, thus shifting the overall emission profile of the ureasil. A similar trend is observed in the corresponding excitation spectrum, as shown in

Figure

(a)
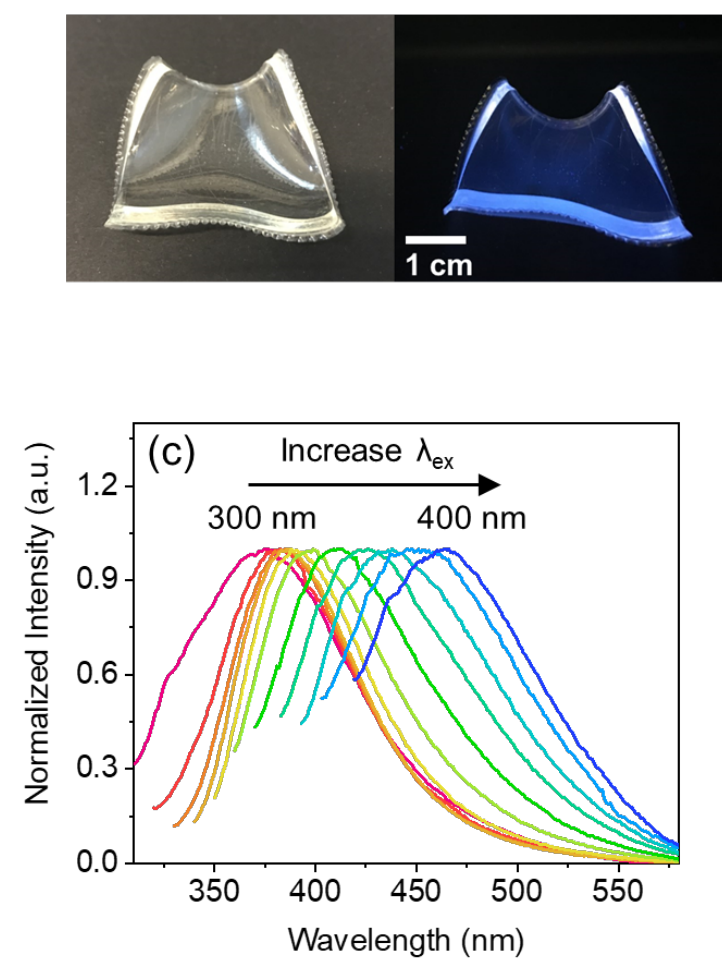
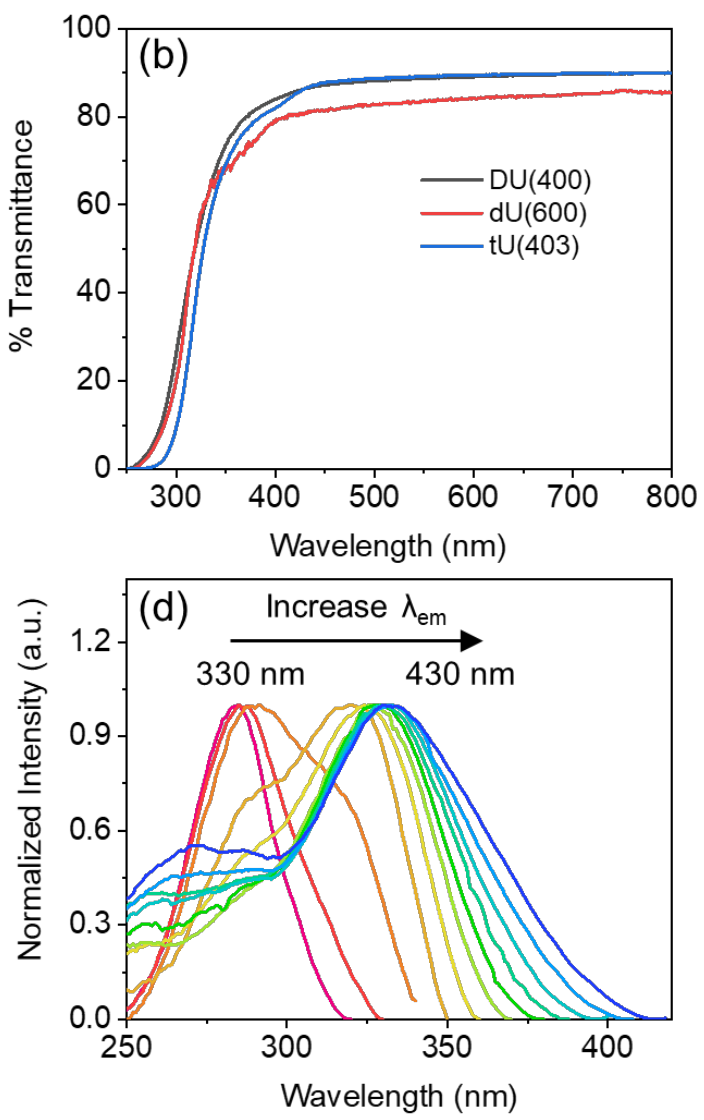

Figure 2 - Optical properties of ureasil monoliths fabricated via the sol-gel process. (a) Photographs of DU(400) under daylight conditions (left) and $365 \mathrm{~nm}$ UV irradiation (right). (b) UV-Vis transmittance spectra of ureasils with different cross-linked structures. (c) Emission spectra and (d) Excitation spectra of DU(400) as function of excitation and emission wavelengths, respectively. 


\section{FTIR spectroscopy in the Amide I region}

The Amide I region (1600-1740 $\left.\mathrm{cm}^{-1}\right)$ of the FTIR spectrum can give direct insight into the specificity and extent of hydrogen-bonding interactions within the ureasil structure. ${ }^{15}$ We observe that depending on the Jeffamine ${ }^{\circledR}$ used to prepare the ureasil, the type of interactions between $\mathrm{N}-\mathrm{H}$ hydrogen bonding groups and carbonyl oxygen atoms on neighbouring polymer chains are varied. Combined Gaussian and Voigt functions were used to model the Amide I band, with up to four components required to describe each sample (Figure 3a-c). Peak 1, centred at roughly $1625 \mathrm{~cm}^{-1}$ arises from ordered direct hydrogen-bonding from N-H to $\mathrm{C}=$ Oon neighbouring chains. Peaks 2 and 3 (centred at $1645 \mathrm{~cm}^{-1}$ and $1700 \mathrm{~cm}^{-1}$, respectively) result from urea-polyether interactions of decreasing order and strength, and Peak 4, centred at $1720 \mathrm{~cm}^{-1}$, represents unbound urea groups within the structure (Figure $3 \mathrm{~d}$ ).
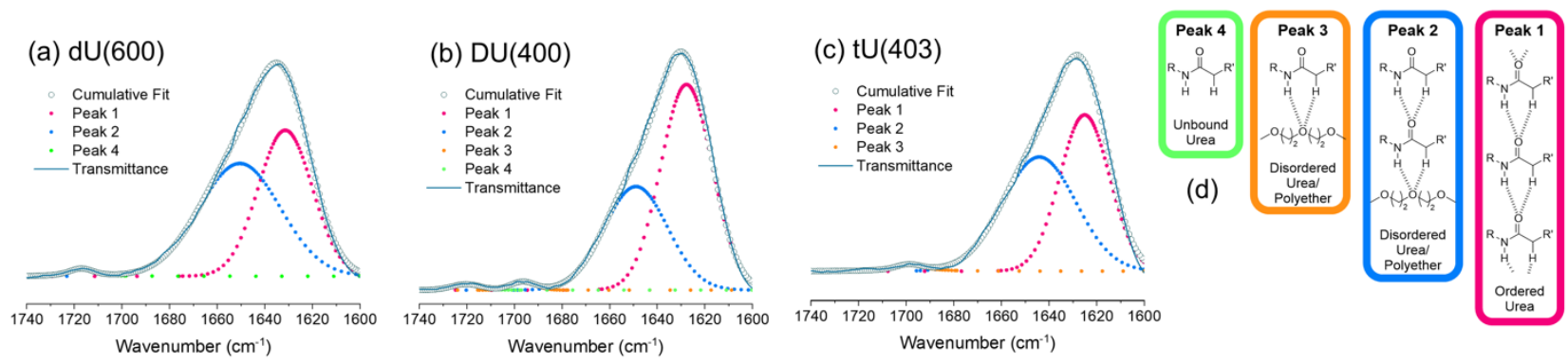

Figure 3 - FTIR spectra of the amide I region (solid line) and associated peak fits (filled circles) for (a) dU(600); (b) $\mathrm{DU}(400)$ and (c) tU(403). (d) Schematic representation of the hydrogen-bonding associations in ureasil hybrids and corresponding peak fits (circles in a-c). R and R' represent the inorganic and organic portion of the hybrid structure, respectively.

Table 1shows the integrated areas and centres obtained from peak fitting to the FTIR spectrum for each sample. Whilst all samples had significant contributions from ordered urea and disordered urea/polyether interactions (peaks 1 and 2 respectively), the ratios did vary. While both $\mathrm{dU}(600)$ and $\mathrm{tU}(403)$ show comparable levels of each species, $\mathrm{DU}(400)$ exhibited a significantly increased contribution from Peak 2 . All samples also show some minor peaks. Firstly, the more disordered urea/polyether contribution (Peak 3) is seen in both of the poly(propylene glycol) homopolymer-based gels, $\mathrm{DU}(400)$ and tU(403). The second minor peak observed is that related to free, unbound urea groups (Peak 4), which was observed for both of the difunctional materials, $\mathrm{dU}(600)$ and $\mathrm{DU}(400)$, but was not observed in the tribranched $\mathrm{tU}(403)$.

Table 1 - Integrated peak areas and peak centres for deconvoluted FTIR spectra of ureasils in the Amide 1 region.

\begin{tabular}{|c|c|c|c|c|c|c|c|c|}
\hline & \multicolumn{2}{|c|}{ Peak 1 } & \multicolumn{2}{c|}{ Peak 2 } & \multicolumn{2}{c|}{ Peak 3 } & \multicolumn{2}{c|}{ Peak 4 } \\
\hline Sample & $\begin{array}{c}\text { Integrated } \\
\text { Area (\%) }\end{array}$ & $\begin{array}{c}\text { Peak } \\
\text { Centre } \\
\left(\mathbf{c m}^{-1}\right)\end{array}$ & $\begin{array}{c}\text { Integrated } \\
\text { Area (\%) }\end{array}$ & $\begin{array}{c}\text { Peak } \\
\text { Centre } \\
\left(\mathbf{c m}^{-1}\right)\end{array}$ & $\begin{array}{c}\text { Integrated } \\
\text { Area (\%) }\end{array}$ & $\begin{array}{c}\text { Peak } \\
\text { Centre } \\
\left(\mathbf{( c m}^{-1}\right)\end{array}$ & $\begin{array}{c}\text { Integrated } \\
\text { Area (\%) }\end{array}$ & $\begin{array}{c}\text { Peak } \\
\text { Centre } \\
\left(\mathbf{c m}^{-1}\right)\end{array}$ \\
\hline dU(600) & 45.66 & 1631 & 52.89 & 1650 & - & - & 1.44 & 1717 \\
\hline DU(400) & 60.27 & 1627 & 37.55 & 1648 & 1.18 & 1696 & 1.00 & 1720 \\
\hline tU(403) & 47.28 & 1625 & 51.07 & 1644 & 1.64 & 1698 & - & - \\
\hline
\end{tabular}

\section{Mechanical properties}

The results from the mechanical testing of the ureasils are presented in Figure 4. The 4-point bending curves were found by multiplying the force on the sample by a constant dependent on sample shape and plotting this against the position of 
the loading points. The gradient of this gives the flexural modulus of the sample. It was observed that the flexural moduli followed the order $\mathrm{tU}(403)>\mathrm{DU}(400)>\mathrm{dU}(600)$ (Table 2). The elastic modulus is obtained from the gradient in the linear portion of the stress-strain curves (Figure $4 \mathrm{~b}, \mathrm{~d}, \mathrm{f}$ ). The calculated elastic moduli show the same trend as the flexural moduli, with tU(403) being more stiff than the other samples (Table 2). dU(600) is more flexible than DU(400), which may be due to the inclusion of the polyethyleneoxide (PEO) block in the backbone being less rigid than the polypropyleneoxide (PPO) blocks which make up DU(400). The Jeffamine ${ }^{\circledR}$ precursor used to make dU(600) also has a slightly higher molecular weight than DU(400), which should also lead to decreased stiffness. The silica-to-polymer ratio also varies between samples, following the order $\mathrm{tU}(403)>\mathrm{DU}(400)>\mathrm{dU}(600)$. This affects the number of siliceous domains present in the sample, with a larger number expected to lead to increased sample stiffness
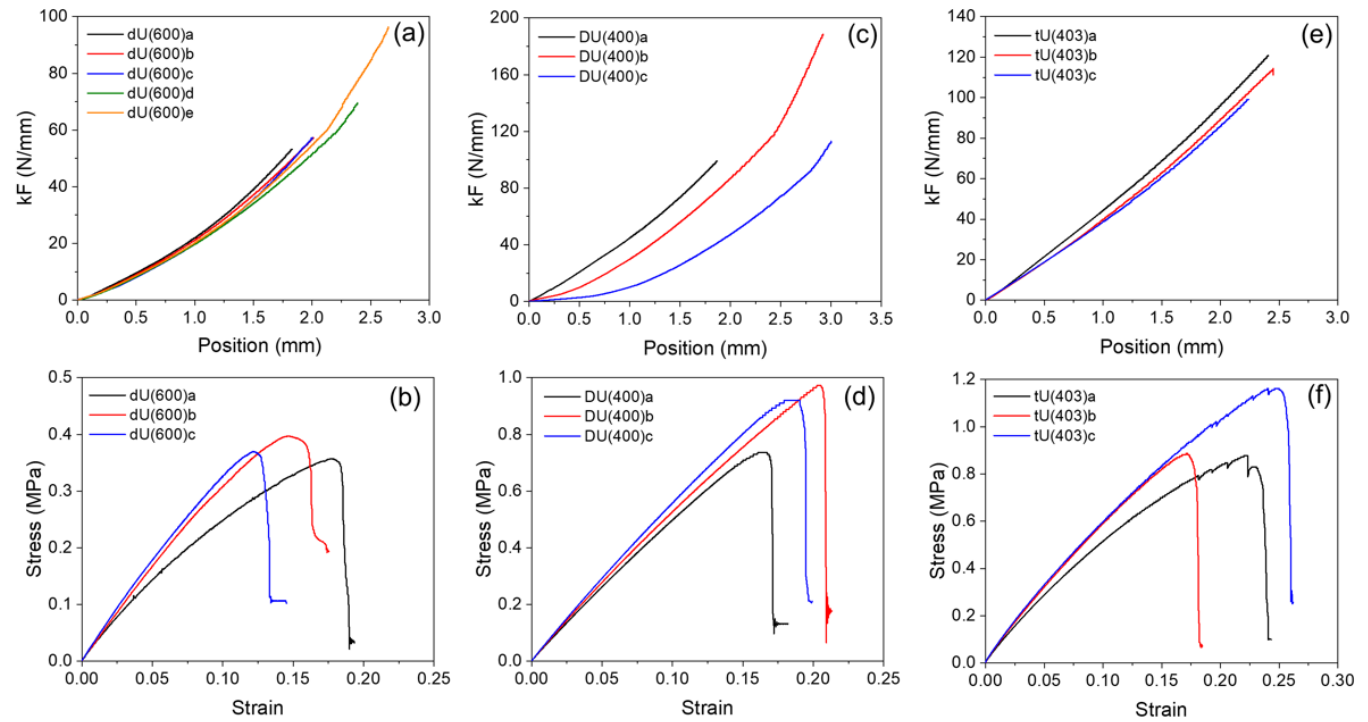

Figure 4 - Mechanical properties of ureasils. (a,c,e) 4-point bending and (b,d,f) tensile testing data from dU(600), DU(400), and $\mathrm{tU}(403)$, respectively. $\mathrm{dU}(600)$ showed the lowest moduli $(\mathrm{a}, \mathrm{b})$ as found by a linear fit to the first 100 points of data in tensile testing and 500 points in 4-point bending. $\mathrm{tU}(403)$ had the highest moduli due to its higher cross-linking density(e,f). $\mathrm{DU}(400)$ showed intermediate properties (c,d).

Table 2 - Elastic and flexural moduli of dU(600), DU(400), tU(403).

\begin{tabular}{|c|c|c|}
\hline Ureasil & Elastic modulus (MPa) & Bending modulus (MPa) \\
\hline dU(600) & $3.529 \pm 0.015$ & $12.416 \pm 0.040$ \\
\hline DU(400) & $5.913 \pm 0.015$ & $21.712 \pm 0.332$ \\
\hline $\mathbf{t U ( 4 0 3 )}$ & $7.144 \pm 0.031$ & $34.360 \pm 0.091$ \\
\hline
\end{tabular}

\section{Water contact angle measurements}

Figure 5 shows representative examples of the water droplet contact angle for each sample. $\mathrm{dU}(600)$ was found to be the most hydrophobic of the samples with a water contact angle of $79.73 \pm 9.59^{\circ}$. This was attributed to the network possessing the lowest silica content (13.50 wt \%) of the tested samples. However, DU(400) and tU(403) samples had comparable water contact angles of $65.54 \pm 4.41^{\circ}$ and $63.94 \pm 4.33^{\circ}$, respectively, despite having slightly different silica contents $(17.40 \%$ and $19.74 \%$, respectively). The lack of differentiation between these samples may possibly be accounted for by the presence of free urea groups within DU(400), and corresponding lack in $\mathrm{tU}(403)$, as shown in the 
FTIR spectra (Error! Reference source not found.), counteracting the decreased silica content. This correlation will be examined in more detail in future

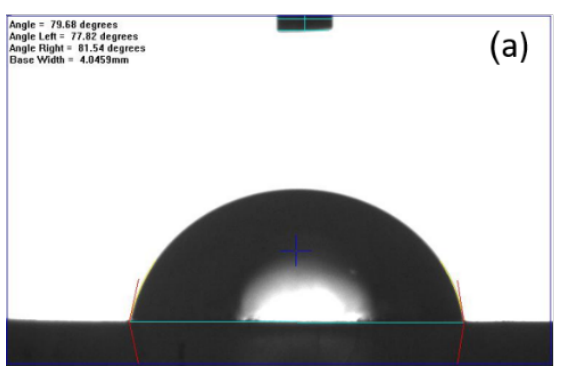

Figure 5 - Representative water contact angle measurements on

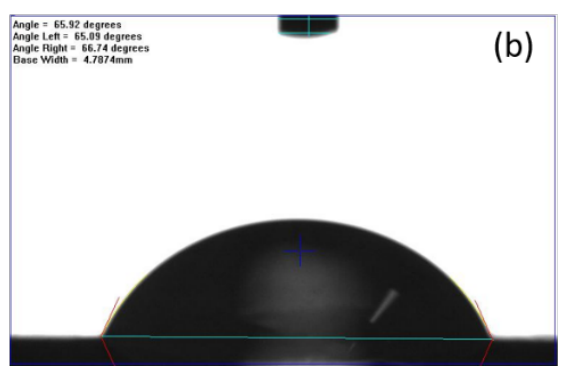

(a) $\mathrm{dU}(600)$,

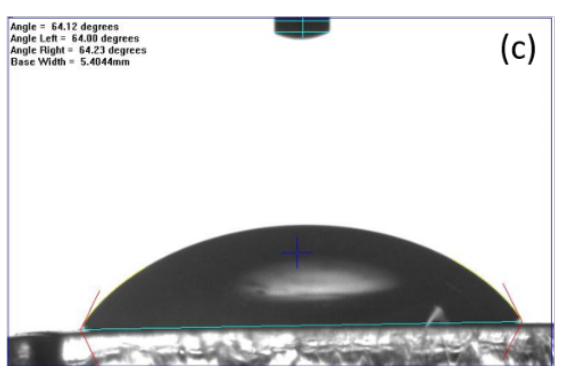

(b) $\mathrm{DU}(400)$, and (c) $\mathrm{tU}(403)$.

\section{CONCLUSIONS}

A series of ureasil polymer monoliths, $\mathrm{DU}(400), \mathrm{dU}(600)$ and $\mathrm{tU}(403)$, were synthesised from low molecular weight Jeffamine ${ }^{\circledR}$ polymeric precursors, which differed moderately in the degree of branching, chemical composition and/or molecular weight. Their mechanical and optical properties were compared to assess their relative suitability in a waveguide application. All samples showed high transmittance in the visible region. FTIR showed significant contributions of ordered urea and disordered urea/polyether hydrogen bonding interactions to the amide I region in all samples. Both difunctional materials, DU(400) and dU(600), showed the presence of unbound urea. The increased hydrogen bonding and silica content of $\mathrm{tU}(403)$ led to an increased stiffness measured by both elastic and flexural moduli compared to DU(400). In contrast, $\mathrm{dU}(600)$ showed intermediate properties due to its slightly higher molecular weight backbone and the presence of PEO in the backbone. $\mathrm{dU}(600)$ was shown to be the most hydrophobic sample, as was expected from its lower silica content in comparison to the other samples. In this study, we have explored the relationship between the hybrid structure of the ureasil and its resulting mechanical and optical characteristics, which will hopefully provide valuable insight into further developing waveguide materials with desirable and tunable properties for a given application.

\section{ACKNOWLEDGEMENTS}

This project has received funding from the European Research Council (ERC) under the European Union's Horizon 2020 research and innovation programme (grant agreement No. 818762 - SPECTRACON). T. J. F. S. thanks the EPSRC (EP/N509620/1) for financial support.

\section{REFERENCES}

1 V. Fattori, M. Melucci, L. Ferrante, M. Zambianchi, I. Manet, W. Oberhauser, G. Giambastiani, M. Frediani, G. Giachi and N. Camaioni, Energy Environ. Sci., 2011, 4, 2849-2853.

2 F. Rey-García, C. Gómez-Reino, M. T. Flores-Arias, G. F. De La Fuente, A. Durán and Y. Castro, Thin Solid Films, 2011, 519, 7982-7986.

3 M. Buffa, S. Carturan, M. G. Debije, A. Quaranta and G. Maggioni, Sol. Energy Mater. Sol. Cells, 2012, 103, $114-118$.

4 V. T. Freitas, L. Fu, A. M. Cojocariu, X. Cattoën, J. R. Bartlett, R. Le Parc, J. L. Bantignies, M. Wong Chi Man, P. S. André, R. A. S. Ferreira and L. D. Carlos, ACS Appl. Mater. Interfaces, 2015, 7, 8770-8778.

5 M. M. Nolasco, P. M. Vaz, V. T. Freitas, P. P. Lima, P. S. André, R. A. S. Ferreira, P. D. Vaz, P. Ribeiro-Claro and L. D. Carlos, J. Mater. Chem. A, 2013, 1, 7339-7350.

6 D. C. Oliveiras, A. G. Macedo, N. J. O. Silva, C. Molina, R. A. S. Ferreira, P. S. André, K. Dahmouche, V. De 
Zea Bermudez, Y. Messaddeq, S. J. L. Ribeiro and L. D. Carlos, Chem. Mater., 2008, 20, 3696-3705.

7 S. C. Nunes, V. De Zea Bermudez, M. M. Silva, M. J. Smith, D. Ostrovskii, R. A. Sá Ferreira, L. D. Carlos, J. Rocha, A. Gonalves and E. Fortunato, J. Mater. Chem., 2007, 17, 4239-4248.

8 A. Bastos, B. McKenna, M. Lima, P. S. André, L. D. Carlos, R. C. Evans and R. A. S. Ferreira, ACS Omega, $2018,3,13772-13781$.

9 M. M. Silva, S. C. Nunes, P. C. Barbosa, A. Evans, V. de Zea Bermudez, M. J. Smith and D. Ostrovskii, Electrochim. Acta, 2006, 52, 1542-1548.

10 I. Meazzini, N. Willis-Fox, C. Blayo, J. Arlt, S. Clément and R. C. Evans, J. Mater. Chem. C, 2016, 4, 40494059.

11 L. Fu, R. A. Sá Ferreira, N. J. O. Silva, L. D. Carlos, V. De Zea Bermudez and J. Rocha, Chem. Mater., 2004, 16, 1507-1516.

12 L. Fu, R. A. Sá Ferreira, M. Fernandes, S. C. Nunes, V. de Zea Bermudez, G. Hungerford, J. Rocha and L. D. Carlos, Opt. Mater. (Amst)., 2008, 30, 1058-1064.

13 L. D. Carlos, R. A. Sá Ferreira, R. N. Pereira, M. Assunção and V. De Zea Bermudez, J. Phys. Chem. B, 2004, 108, 14924-14932.

14 A. Kaniyoor, B. Mckenna, S. Comby and R. C. Evans, Adv. Opt. Mater., 2016, 4, 444-456.

15 V. De Zea Bermudez, L. D. Carlos and L. Alcácer, Chem. Mater., 1999, 11, 569-580. 